\title{
Concepts of Caring: Uncovering Early Concepts of Care in Practice for First Year Occupational Therapy Students
}

James Battaglia

Hofstra University

Follow this and additional works at: https://encompass.eku.edu/jote

Part of the Occupational Therapy Commons

\section{Recommended Citation}

Battaglia, J. (2019). Concepts of Caring: Uncovering Early Concepts of Care in Practice for First Year Occupational Therapy Students. Journal of Occupational Therapy Education, 3 (1). https://doi.org/10.26681/jote.2019.030102

This Original Research is brought to you for free and open access by Encompass. It has been accepted for inclusion in Journal of Occupational Therapy Education by an authorized editor of Encompass. For more information, please contact Linda.Sizemore@eku.edu. 


\title{
Concepts of Caring: Uncovering Early Concepts of Care in Practice for First Year Occupational Therapy Students
}

\begin{abstract}
Caring for others is a central ideal of most health care professions. The ability to facilitate caring behaviors in occupational therapy students is essential to developing students who are well prepared to provide both technically and emotionally competent care. This study explored the early concepts of care of Master of Science Occupational Therapy students at the start of their graduate education through use of a questionnaire and follow-up interviews. The three most frequently identified student concepts of care were: (1) caring as it relates to time, (2) caring as a personal quality, and (3) caring through their communication with clients. Students also identified more frequently with negative past experiences in their responses but were not consciously aware of the impact of these experiences on their view of caring. Lastly, students were limited in their inclusion of social, cultural and socioeconomic factors in their responses and had difficulty resolving the conflict between treating everyone equally, and modifying care based on the impact of these factors. Results can inform occupational therapy education programs on how best to identify and facilitate comprehensive caring behaviors in students during the educational process. Further, the results provide a baseline for future evaluation of changes in these behaviors and beliefs over the course of the occupational therapy education process.
\end{abstract}

\section{Keywords}

Caring, occupational therapy, education, time, culture

\section{Creative Commons License}

\section{(a) $\mathbb{Q} \Theta \Theta$}

This work is licensed under a Creative Commons Attribution-Noncommercial-No Derivative Works 4.0 License. 


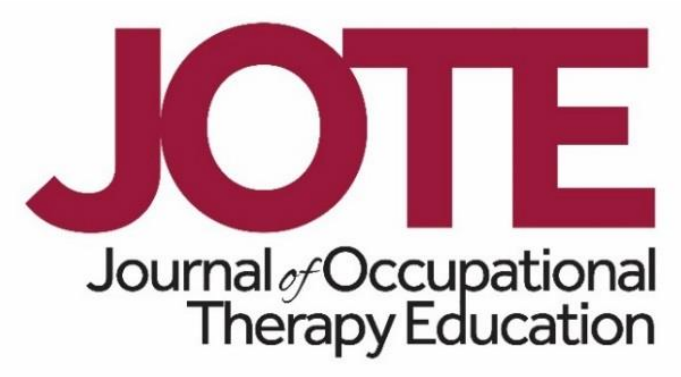

Volume 3, Issue 1

Concepts of Caring: Uncovering Early Concepts of Care

in Practice for First Year Occupational Therapy Students

\author{
James Battaglia, MA, OTR/L CHT \\ Hofstra University \\ United States
}

\begin{abstract}
Caring for others is a central ideal of most health care professions. The ability to facilitate caring behaviors in occupational therapy students is essential to developing students who are well prepared to provide both technically and emotionally competent care. This study explored the early concepts of care of Master of Science Occupational Therapy students at the start of their graduate education through use of a questionnaire and follow-up interviews. The three most frequently identified student concepts of care were: (1) caring as it relates to time, (2) caring as a personal quality, and (3) caring through their communication with clients. Students also identified more frequently with negative past experiences in their responses but were not consciously aware of the impact of these experiences on their view of caring. Lastly, students were limited in their inclusion of social, cultural and socioeconomic factors in their responses and had difficulty resolving the conflict between treating everyone equally, and modifying care based on the impact of these factors. Results can inform occupational therapy education programs on how best to identify and facilitate comprehensive caring behaviors in students during the educational process. Further, the results provide a baseline for future evaluation of changes in these behaviors and beliefs over the course of the occupational therapy education process.
\end{abstract}

\title{
INTRODUCTION
}

The cornerstone of most health care professions is the ideal of caring for others. In some contexts, caring is defined merely as the practice of looking after those unable to care for themselves ("Caring," 2014). This definition fails to encapsulate the entire meaning of caring when providing health care for others. The grander meaning of caring has been defined to include aspects such as displaying kindness and concern, having thought or regard, and showing compassion ("Caring," 2014; "Care," 2014). 
Caring can also incorporate concepts of ethics, social justice, social competence, and multiculturalism (Munoz, 2007). Further, caring for others can be reflected in the ability or willingness to receive new ideas or opinions, become engrossed in the attention or interest of another individual, and engaging in a reciprocal relationship with others toward mutual benefit (Larin, Benson, Wessel, Martin, \& Ploeg, 2014).

As an educator of occupational therapy (OT) students, the importance of developing or enhancing caring behaviors in new graduates cannot be understated. Developing students who are not only technically competent but also highly emotionally competent in their care of others is imperative. Students who see the "big picture," place value in caring, and use these internal skills (often referred to in the profession as "therapeutic use of self") to promote health and well-being in patients, should be the goal of OT education. It is noted, however, that these skills are often hard to teach, and caring behaviors of students are often displayed on a continuum.

When exploring how caring behaviors develop in health care students, Clouder (2005) defined caring as a "threshold concept;" a doorway to true caring behavior which students pass through when experiencing interactions that require the expression of caring for others. According to Clouder (2005), when confronted with these emotional experiences, students developed new and previously inaccessible ways of thinking about caring. It was further asserted that students had to be faced with situations that accrued some sense of emotional capital in order to develop these behaviors. Assumptions were made, however, regarding the absence of true caring behaviors in these students prior to engaging in patient care and having "threshold" experiences. If these assertions were correct, then students who had threshold experiences prior to their OT education (e.g., caring for a sick family member or volunteer experiences) might enter training with an already well-formed construct of caring (Clouder, 2005).

To truly care for a patient, students must also develop relationships grounded in mutuality and intentional respect for a person's culture. According to Munoz (2007), students must develop a concept of care that includes generating cultural knowledge, building cultural awareness, applying cultural skills, engaging culturally diverse others, and exploring multiculturalism. Munoz (2007), however, appeared to assume that students enter educational programs without a cultural foundation. If students had culturally relevant experiences prior to entering their graduate education, one could assume that students might have already developed this aspect of caring for others.

Though caring is a foundational concept in health care, there is a dearth in the OT literature relating to caring behaviors of students. In exploring the nursing and medical literature, however, some important observations regarding caring behaviors and beliefs of health care students have been made. Murphy, Jones, Edwards, James, and Mayer (2009) explored the perception of caring behaviors of first year and third year nursing students. As these students moved through their educational program into clinical practice, the perception of the importance of caring behaviors as part of nursing practice actually decreased. Though caring is a core nursing value, the educational process appeared to have a (counterintuitively) negative effect on the perceived value of caring behaviors when students transitioned into clinical rotations. Murphy and colleagues 
(2009) considered the possibility that students started educational programs with strong beliefs regarding the role of caring in practice and often found political and economic factors driving practice decreased their ability to engage in expressive care.

Furthermore, as practice became more technical, education focused more on developing technical competence, while neglecting social and emotional experiences.

Phillips and colleagues (2015) indicated that new nursing students had insight into caring, and the skills and attributes needed to become ideal care providers. Students entered nursing education with enthusiasm about their future profession and had expectations about how their education would help them develop into better practitioners. Though these students had opinions about what caring looked like in practice, they often had difficulty articulating the concept. Students were able to list tasks and behaviors reflective of caring, and often had an easier time describiing caring in relation to what it was not, rather than what it was (Phillips et al., 2015).

To explore the effect of education on the caring behaviors and attitudes of medical students, Beagan (2003) investigated how exposing third year students to a course in social and cultural issues affected awareness of how social and cultural diversity affected practice, the lives of their patients, and the patient-physician interaction. Beagan found, however, that many of the medical students were unaware of issues related to socioeconomic diversity, racism, sexism, and homophobia (even among fellow students), and had little ability to relate to their own socioeconomic and cultural advantages.

Beagan also noted that many students held the belief that care should be blind, in that all treatment should be identical no matter what social or cultural factors were present. Students often minimized the life contexts of their patients in an effort to provide consistent medical care. This presented a complex dilemma. In one regard, health care providers are frequently told to treat everyone equally to limit disparity of care across social and cultural contexts. In another regard, however, how could any health care provider be truly caring for a patient without first considering factors that might have a profound effect on the way patients perceive, react to, and participate in their care?

Adamson and Dewar (2015) also explored how caring could be made explicit in the curriculum. The authors suggested that for students to be able to provide compassionate care, they must also experience this care themselves. It was important that educators created learning environments that enabled students to be reflective, created meaning of compassionate care, and provided encouragement and opportunities for students to develop, enhance and build on their ability to be caring. These reflective experiences, both good and bad, facilitated students' ability to challenge their own preconceived notions about care and compassion and allowed for further discussion. It was concluded that nurses saw caring compassionately as part of the job, but reflection assisted in recognizing the essential elements.

It was also noted by Adamson and Dewar (2015), however, that although students said they had a strong commitment to being caring professionals, they often found it challenging when they began practice. This mirrors the findings of Murphy and colleagues (2009) as they too hypothesized that the transition from student to clinician can often challenge the new clinician's concept of caring. This study reflected the need 
to understand how students conceptualized caring through their own experiences. To fully understand the effects of the educational process on caring, however, one must first understand the preconceived concepts held by students.

\section{METHODS}

\section{Research Site and Participants}

Participation was solicited from a single cohort of entry level Master of Science in Occupational Therapy students at a local private university in New York. These students were entering their second semester of training and consisted of both female $(n=8)$ and male students $(n=2)$. Students ranged in age from 21 to 35 years and originated from New York, New Jersey, Rhode Island, and Michigan. Students were representative of four different races (Asian = 3, African American =1, Hispanic = 1, and White = 5). Due to the small size of the cohort, all ten students were solicited for participation. Of the ten students, nine chose to participate in the initial portion of this study. In an effort to keep the questionnaire anonymous, demographic data were not collected on each questionnaire, therefore the student that did not participate is unknown.

At the conclusion of this initial phase (i.e., phase one), students were then asked to volunteer for phase two of the study which included an in-person interview. Of those who volunteered, three respondents were chosen for participation based on their prior ability to be verbally engaging during classroom experiences with the researcher. Only three students were chosen due to time constraints of the study. This study was reviewed and approved by the institution's Institutional Review Board (IRB) and all participants signed an Informed Consent for participation.

\section{Data Collection and Analysis}

This qualitative phenomenological study collected data using two different methods in two phases: written questionnaire and interviews. During phase one, a seven-question written questionnaire was utilized to elicit baseline responses to questions regarding student perspectives on caring in health care and how educational experience influenced perspectives on caring. Students were provided with the questionnaire during the second semester of their OT graduate education. A two-week deadline to return the completed questionnaire in an unmarked envelope to the researcher's university mailbox was provided. At the end of the questionnaire, students were offered the opportunity to participate in phase two interviews. Although the students were not asked to do so, all students who agreed to participate in phase two disassociated their contact information from their questionnaires. This, unfortunately, limited the ability to connect questionnaires to specific students. In-person interviews, therefore, were based on the larger global concepts presented by phase one. Individual interviews were digitally recorded to ensure accuracy of transcription.

Data analysis began with a review of the questionnaire responses. First, each questionnaire was analyzed as its own isolated set of data to identify the individual student's concepts of caring. Each questionnaire was then coded, and themes were created. Following this initial analysis, all answers across all questionnaires were categorized. These common themes were then used to develop the interview protocol. 
Phase two interview questions discussed global concepts of caring, as well as trends not reported in previous studies. These one hour in-person interviews were used to clarify and triangulate responses on the questionnaire and further explore the concepts presented in the cohort's collective responses. Once all the questionnaire and interview questions were coded and categorized, the data were again analyzed to identify major themes presented in both stages of the study. Conclusions were drawn from these data analyses.

\section{Validity and Ethical Considerations}

Entering into this study with a preconceived concept of caring was a concern of the researcher regarding interpretation of data. One attempt to decrease this threat was through triangulation using multiple modes of exploration and analysis (e.g., using both a questionnaire and follow up in-person interviews). Having the students who performed in-person interviews clarify and expand on global responses and themes assisted in gaining a better understanding of what the students in phase one were trying to communicate. Researcher bias could have also affected the wording of the questionnaire and interview questions. The questionnaire was therefore read by an outside reader to get an unbiased perspective on question quality and appropriateness.

Using participants who were students in the program where the researcher was an instructor may have also influenced responses. Students might have felt they had to give certain answers to protect themselves, faculty members, and/or the program in general. Further, the power relationship present between the researcher and the students posed an ethical dilemma as students may have felt obligated to participate, limiting their autonomy. The effects of this power relationship between the students and researcher was minimized by making participation optional, by making the questionnaires anonymous, and by making the follow up interviews voluntary and confidential with use of pseudonyms.

\section{PHASE ONE FINDINGS}

\section{Individual Themes and Concepts}

Data from the nine individual questionnaires were evaluated, and individual concepts and themes were identified for each student's response set. Individual questionnaires uncovered both unique and shared perspectives on caring behaviors. The most consistent concept of caring across questionnaires was the concept of time. These temporal aspects of care were largely unexpected and were unrepresented in the literature. Responses regarding time included practitioners who were on time, who did not spend time on technology, who used their time to provide exceptional care, or who gave the clients enough time to express themselves. Only one student provided a unique perspective from the others, which expressed the importance of addressing cultural and social needs of the client. This is reflective of the concepts presented by Munoz (2007), however none of the other students made this reference. 


\section{Evaluation of Each Questionnaire Question}

When each question was individually evaluated and categorized across response sets, recurring themes across several concepts were noted. Table 1 provides a summary of these themes, keywords identified in each question, and examples of representative responses. For question one, which asked students to describe caring in the context of health care, students responded with a wide variety of answers fitting into five different categories: (1) caring as a personal quality, (2) caring as a business, (3) caring through their communication with clients, (4) caring as it relates to time, and (5) caring through demonstration of skill. Some of these concepts were similar to those discussed by Phillips and colleagues (2015) and Adamson and Dewar (2015), but some were novel and unexpected. Though it was largely anticipated that students would report aspects of skill, communication, and personal qualities, two areas, "caring as it relates to time" and "caring as a business," were not previously considered.

Table 1

Questions One to Seven: Summary of Results by Theme, Representative Keywords, and Examples of Responses

\begin{tabular}{|c|c|c|}
\hline Themes & $\begin{array}{l}\text { Representative Keywords by } \\
\text { Question Number }\end{array}$ & Examples of Responses \\
\hline $\begin{array}{l}\text { Caring as a } \\
\text { personal } \\
\text { quality }\end{array}$ & $\begin{array}{l}\text { 1. Personality trait, being } \\
\text { empathic, being } \\
\text { approachable, listening to } \\
\text { others } \\
\text { 2. Being friendly, mannerisms } \\
\text { and gestures, being attentive } \\
\text { 3. Touch of nurse, greeted } \\
\text { with a smile, charming, funny, } \\
\text { giving a hug } \\
\text { 5. Patience, empathy, } \\
\text { kindness, service with a smile, } \\
\text { friendly } \\
\text { 6. Considering different } \\
\text { background and needs of } \\
\text { patient, open minded, develop } \\
\text { trust, personalize experience }\end{array}$ & $\begin{array}{l}\text { "... person can be } \\
\text { inherently caring regardless } \\
\text { of context and often times } \\
\text { this character trait may lead } \\
\text { individuals into the health } \\
\text { care field because providing } \\
\text { care for patients delivers a } \\
\text { unique sense of } \\
\text { satisfaction." } \\
\text { "... simple acts of kindness } \\
\text { and respect will be the most } \\
\text { valuable for me to practice } \\
\text { as a caring and } \\
\text { compassionate OT." }\end{array}$ \\
\hline $\begin{array}{l}\text { Caring as a } \\
\text { business }\end{array}$ & $\begin{array}{l}\text { 1.Extrinsically motivated, used } \\
\text { for marketing, providing great } \\
\text { service }\end{array}$ & $\begin{array}{l}\text { "Caring can also be used as } \\
\text { a selling point..." }\end{array}$ \\
\hline $\begin{array}{l}\text { Caring through } \\
\text { their } \\
\text { communication } \\
\text { with clients }\end{array}$ & $\begin{array}{l}\text { 1. Respect for patient needs } \\
\text { and situations, not making } \\
\text { judgements, interacting in an } \\
\text { honest way }\end{array}$ & $\begin{array}{l}\text { "The way the practitioner } \\
\text { speaks to a patient must be } \\
\text { kind, respectful, and } \\
\text { empathic." }\end{array}$ \\
\hline
\end{tabular}




\begin{tabular}{|c|c|c|}
\hline & $\begin{array}{l}\text { 2. Explaining, informing, tone } \\
\text { of voice } \\
\text { 3. Calling the patient to see } \\
\text { how they are, answering } \\
\text { questions, being patient and } \\
\text { reassuring } \\
\text { 4. Talking down to you, not } \\
\text { explaining what they are } \\
\text { doing, reacting poorly to } \\
\text { patient } \\
\text { 5. Speaking on same level, } \\
\text { taking questions into } \\
\text { consideration, making client } \\
\text { understand what is being } \\
\text { done and why, communicating } \\
\text { that you care. } \\
6 \text {. Avoid rudeness, making } \\
\text { clients feel unheard, belittled } \\
\text { or ignored, avoiding awkward } \\
\text { silence, explain what I am } \\
\text { doing }\end{array}$ & $\begin{array}{l}\text { "...honesty, respecting the } \\
\text { client's personal choices, } \\
\text { and providing personalized } \\
\text { treatments that cater to the } \\
\text { client's concerns and } \\
\text { dynamics." } \\
\text { "It seems basic and simple } \\
\text { but communicating (through } \\
\text { words or body language) is } \\
\text { a valuable skill to have as } \\
\text { an OT." }\end{array}$ \\
\hline $\begin{array}{l}\text { Caring as it } \\
\text { relates to time }\end{array}$ & $\begin{array}{l}\text { 1. Being on time, not making } \\
\text { patients wait, giving patients } \\
\text { attention, not rushing anyone, } \\
\text { making treatment worth the } \\
\text { patient's time } \\
\text { 2. Being considerate of } \\
\text { patients' time, not rushing, } \\
\text { limiting time behind computer } \\
\text { 3. Taken on time, took time } \\
\text { with me, wasn't rushed } \\
\text { 4. Being late, long wait, } \\
\text { waiting for appointments, put } \\
\text { on hold, being rushed } \\
5 \text {. Time is important, not } \\
\text { rushing, promptness, being } \\
\text { timely } \\
6 \text {. Avoid lateness, don't rush } \\
\text { patients, limit productivity } \\
\text { issues }\end{array}$ & $\begin{array}{l}\text { "Reassuring patients that } \\
\text { seeking your professional } \\
\text { expertise is worth their time } \\
\text { and is not meaningless." } \\
\text { "I think being timely and } \\
\text { never allowing my clients to } \\
\text { feel rushed or that their } \\
\text { sessions aren't worth my } \\
\text { time is very important." } \\
\text { "I felt rushed and even as if } \\
\text { I was an inconvenience for } \\
\text { the staff at the clinic. I had } \\
\text { my sentence cut off by the } \\
\text { practitioner." }\end{array}$ \\
\hline $\begin{array}{l}\text { Caring through } \\
\text { demonstration } \\
\text { of skill }\end{array}$ & $\begin{array}{l}\text { 1. Making proper clinical and } \\
\text { ethical decisions, displaying } \\
\text { expertise, using a client } \\
\text { centered approach }\end{array}$ & $\begin{array}{l}\text { "...using proper clinical and } \\
\text { ethical decisions that reflect } \\
\text { helping individuals improve } \\
\text { through their services." }\end{array}$ \\
\hline
\end{tabular}




\begin{tabular}{|l|l|l|}
\hline & $\begin{array}{l}\text { 2. Answering questions and } \\
\text { explaining the role of OT, } \\
\text { reviewing medical history, } \\
\text { methods of touching } \\
\text { 3. Reviewed chart and knew } \\
\text { condition, informative, } \\
\text { providing correct diagnosis }\end{array}$ & Profile." \\
& \\
\hline
\end{tabular}

Note: Keywords are organized by question number (e.g., $1-6)$. Not all themes are represented in each question response set.

In question two, students were asked to describe what caring behaviors looked like in practice. Students provided answers similar to question one, but no longer discussed issues of caring as a business. Students were then asked in question three to describe an instance where they felt they were well taken care of by a health provider. Students frequently reported experiences with providers who were able to express care and concern for them while taking their time and not rushing treatment.

Students were also asked, in question four, to describe instances when they did not feel well taken care of by their health care provider. Eight of the nine students reported having a bad experience with a health care provider in the past. Five of the eight students referred to the concept of time when relating to bad experiences. Many of these students also referred to professionals who had difficulty proving care with good interpersonal skill (i.e., caring through communication with the client).

For question five, students were asked to reflect on the responses provided in questions three and four, in order to describe aspects of care they felt would be most valuable in their practice as an OT. A majority of responses represented a combination of three factors: (1) time, (2) personal qualities of the provider, and (3) the provider's ability to communicate with the patient. Time and personal qualities were referred to most often.

In question six, students were asked to reflect on their negative experiences in health care, the qualities of providers they found uncaring, and how these negative experiences shaped their view of being a caring practitioner. One student had difficulty formulating any answer, responding, "I am not really sure what specific things to avoid. I feel like I will learn things as I get more experience." Some responses were also based on prior negative experiences, while others were seemingly unrelated. Students reported wanting to avoid deficits in communication, issues with time, and providing care in a way that is not reflective of their personal caring characteristics.

Finally, in question seven, students were asked to relate the concept of caring to their educational experiences. The intent was to discover if students recognized instances of in-class experiences that influenced their view of caring. Almost all the students related to experiences outside of the classroom, prior to their OT education (e.g., practitioners observed treating a family member or as a volunteer), or in Level I Fieldwork during their first semester. One student reflected on a negative fieldwork experience when a teacher did not show caring for a preschooler and used this negative experience to 
shape his or her perspective on caring. This student stated, "...I used to view caring as a simple thing; just being kind to others. However, now I see that communicating in a kind and caring way does not come naturally. It is not so simple for everyone." Of the remaining students, one stated having difficulty answering the question due to a lack of experiences, and only two provided actual in-class experiences during the coursework portion of their education.

Of the two responses that did reflect actual in-class experiences, one student had prior experiences in another OT program that made him or her question the caring nature of the profession. The student stated, "I unfortunately had the experience of interacting with professors who do not practice what they preach...You would think for a profession that is all about empathy and care would show a bit more compassion." Another student discussed the influence of coursework, stating "...I believe my coursework has changed the way that I view caring for others in practice...therapeutic use of self is important in establishing good relations with clients."

\section{Interpretation of Questionnaires and Development of Concepts for Phase Two} While students began their OT education with similar overall ideas related to caring, individual perspectives varied. Although most students, at some point, acknowledged the importance of being compassionate and empathic, they also provided some unanticipated responses. The most novel and consistent perspective was the aspect of time as a representation of caring, which had not been identified previously.

As noted in the literature (Adamson \& Dewar, 2015; Phillips et al., 2015), students also appeared to have an easier time reflecting on and relating to negative experiences when formulating concepts of caring. Responses included both positive behaviors students looked to integrate into care, and negative behaviors they looked to avoid, based on prior negative experiences. The initial answers regarding how students identified care and how it looked in treatment often did not correlate with answers on how care will eventually be integrated into their own practice. Student $C$, for example, reported caring in practice as,

...one where a client feels as though they are the most important individual in the room. They feel respected for who they are as a person whether they are ill or have a disability. They never feel judged and they are spoken to in a manner where they feel that their opinion is heard and taken seriously.

This correlated with student C's negative experience of waiting two hours to be seen and then being told not to waste the practitioner's time. The student also noted an instance where a doctor's office did not respect her desire for privacy and a same-sex provider. When the student was asked what aspects of her experiences she felt were most valuable in her own practice, the first response was related to being timely and never allowing clients to feel rushed or that their sessions were not worth her time.

An area minimally represented in the initial questionnaire response set was the role of culture in caring. Though Munoz (2007), conceptualized caring in health care education as incorporating aspects of being culturally responsive and competent, only one student 
referred to providing care that was culturally, socially, or contextually relevant to the patient. This was a surprising omission from the responses because so much is said in OT education about being mindful of patients' life contexts.

Lastly, when asked about experiences during their OT education, many students had difficulty relating transformational experiences directly to the classroom. As noted earlier regarding educational experiences, only two students were able to connect something experienced during classroom experiences to their perspective on caring. All other responses to this question related to either experiences prior to their OT education during volunteer or observation hours, fieldwork level I, or experiences with family members.

\section{PHASE TWO FINDINGS}

\section{Phase Two participants}

Phase two involved in-person interviews of three students. Emily and Abigail were both white females in their early twenties who originated from the Midwest, while Sylvester was a Hispanic male in his early twenties from one of the boroughs of New York. Emily had a background in the health sciences and volunteered in rehabilitation centers back home. Abigail had a background in psychology and had volunteer experiences in health care prior to starting the program, and Sylvester had a background in exercise science and worked and volunteered in health settings in the boroughs of New York. Each interview was performed individually and in-person with the researcher.

Interviews followed a similar interview protocol and addressed themes developed during phase one of the study. The main concepts discussed during the interviews were: (1) the significance of time as a component of caring and perceived impact of time on future practice, (2) students relating strongly to negative past experiences when forming their view of caring in practice, (3) the impact of the educational process and experiences on the student's view of caring, and (4) the importance of culture and socioeconomic status in providing care as being a component of caring.

\section{Themes and Concepts Presented by Interviews}

Time. Time was a consistent theme throughout all written questionnaires in phase one and was explored in phase two. Though time was recognized by each of the students interviewed as a factor or component of caring (to a different extent), each interpreted time in a slightly different manner. Emily related strongly to the concept of time as a significant aspect of caring in practice. Practitioners who seemed rushed and not present during the session made her feel less cared for and less important. Abigail identified caring more as an expression of professionalism, though she did relate to experiences where she was made to wait extended periods of time for a practitioner and felt less cared for. She also noted there were times during her volunteer experience that patients would get agitated if they were brought to the therapy room and were not seen right away, leaving them angry and feeling neglected. Sylvester also had a different perspective regarding time. Although Sylvester identified time as a reflection of care as 
a personal quality with the practitioner providing attention and focus, he also saw time as a function of medicine as a business. Sylvester reflected on times he watched practitioners rush through the end of the day so they could leave on time, or seeing as many people as possible in a day trying to make as much money as possible.

All three students, when asked what they would do if they worked somewhere time was an issue, reported they would resolve the issue of limited time through communicating in a caring way. Discussing with the patient that even though time was an issue, the patient would remain their number one priority. Abigail stated, "Maybe letting them know a little bit ahead of time, you know there is going to be other people coming and I want you to know that you are still a priority..." Further, Emily stated, "You know, we are on a tight time frame here, but I am going to try to do my best to get you the materials and resources you need..." For Sylvester, communicating effectively with patients in general reflected care, regardless of the topic (e.g., talking about the patient's favorite sport, etc.) and thought it was integral to providing good care.

When asked if they thought the connection to time was unique to their generation, responses were mixed. Though all three identified time as an issue for their generation, as everything is immediate and easily accessible, Abigail and Sylvester both recognized instances of older generations being impacted by issues of time as well. Abigail reflected on her experience with elderly patients, and Sylvester reflected on experiences in doctors' offices with his mother, as she too had expectations of visits being timely and lateness impacted her perception of care.

Negative past experiences shaping concepts of care in practice. Another common theme present throughout responses was the impact of negative past experiences on the shaping of beliefs regarding caring in practice. Though this was not explicitly explored in phase one, it became apparent during analysis of answers that negative experiences directly impacted the students' view of caring. Most of the students who responded to the questionnaire had representations of their negative experiences within their concepts of what caring should look like in practice. This theme was explored further with all three students during interviews in phase two.

A common finding among all three students was the connection between negative experiences and concepts of caring was not a conscious process. The students were not readily aware of how their negative experiences with practitioners had impacted their view of what caring looked like and how it influenced their future practice patterns and beliefs. All three students reported that positive experiences did not resonate as much as negative experiences because positive experiences were expected of their practitioners. Negative experiences were often unexpected and impactful. Abigail reported, "I expect to receive caring...It is an expectation rather than a privilege or something you see as a benefit of good care." Abigail's negative experiences involved feeling her privacy was violated when her doctor's office disregarded her request for a same-sex practitioner and admits she values privacy more than other aspects of care. Though she was not readily aware, Abigail had already begun integrating her negative experiences into her own view of caring for others. Sylvester went further to state that 
students came into the program with an ideology about caring in practice that often led them to feel dissatisfaction and disappointment when they entered practice themselves. He felt the reality of providing care often did not match with student ideals.

The impact of educational experiences. During phase one of the study, students appeared to have difficulty identifying experiences within the classroom that could have an influence on their caring behaviors. Students frequently cited experiences outside of, and prior to, the program as volunteers or with family members. Students also related strongly to their fieldwork level I experiences. In phase two, the students were again asked about classroom experiences they felt could influence their caring behaviors. The students continued to have a hard time conceptualizing experiences within the program. Both Emily and Abigail felt strongly about how fieldwork experiences would help shape these behaviors, as they would have a supervisor present who could provide feedback and model proper behaviors as they worked through real-life situations rather than situations provided in a text book. Abigail did recognize and value that her professors, who were also practitioners, often brought this situational learning to the classroom which allowed students to conceptualize how they might handle these situations. Classes where students had an open forum where they could work through these situations were identified as beneficial.

When asked again specifically how classroom activities could influence behaviors, Emily stated she thought it could be important to have someone simulate interactions in the classroom under the guidance of a professor. Though she was unaware of the term, Emily was describing the use of standardized patients. When presented with the idea, she was enthusiastic about having an outside person come into class acting as the patient while students got a chance to practice these skills in a safe and guided environment. It allowed students to make mistakes in a low stakes environment, while receiving immediate feedback and instruction.

Finally, Sylvester had difficulty at first, identifying how the program could influence his caring behaviors in practice because the process was all very new to him. He felt he still possessed certain ideals regarding caring from when he entered the program but was sure he would learn more about patient interactions that might influence his beliefs. Of the students in both phase one and two, Sylvester was also the only student to mention the potential role of mentoring within the program and thought it would be key to connecting what happened in the classroom to what happens in the clinic. Mentoring would provide the student a way to connect with an experienced therapist or faculty member to discuss situations that posed challenges to the student. In relation to the eight other students in phase one and two, it was unclear if they did not find value in mentoring or if they had never experienced mentoring in order to relate to it as it was not mentioned by anyone else.

The importance of culture and socioeconomic status. During phase one of the study, only one student referred to providing care that was culturally, socially, or contextually relevant to the patient as a component of caring. This was a surprising omission. As part of phase two, students were therefore asked to balance the idea of 
treating everyone the same versus treating patients individually, according to the context of their lives. This posed a dilemma for the students with each student relating differently to the scenario.

Emily admitted she had not thought of the role of culture but could see value in understanding cultural and contextual factors that impacted the lives of her patients. She also struggled with the idea of treating patients differently based on culture and context, but acknowledged these factors do direct patient-centered care. Emily stated,

...So yes and no, I mean yes. We should treat everyone the same as far as race and ethnicity, and gender and socioeconomic status. But should you treat everyone the same within the same diagnosis? No, because now you're completely going against what client-centered practice is and each treatment should be tailored to the person and in the rapport that you create with the client.

For Abigail it was clear, that culture and other life contexts were inseparable from OT practice. Culture really mattered in forming the way caring for others was approached. She stated, "... if I felt like there was an aspect of me that was just cut out when I was being treated I wouldn't feel like I was receiving the best level of care and less compassionate care." Although she placed great importance on culture and being culturally competent, Abigail noted she had not considered it in her responses, quite possibly because she was not a minority and most people know and understand the practices of her culture; something she often took for granted. She acknowledged that she most certainly would have to face cultural and other life contexts with patients, but was not sure how to prepare for it.

Sylvester was intrinsically motivated to treat everyone the same to be fair and unbiased, however, he also connected with the idea that sometimes being mindful of these other factors would reflect greater caring in practice. He struggled with the idea that care would be inequitable across patients but found value in understanding cultural and contextual factors. In many ways, considering these factors translated to a higher level of caring, but at the same time made Sylvester feel like he was providing less care for another patient who might not have the same needs. He stated, "It is a really tough situation...Can you care for someone without considering those things?"

\section{INTEGRATION OF PHASE ONE AND TWO WITH DISCUSSION}

Phase one and two provided both expected and unexpected responses regarding students' concepts of caring in practice and the role of the educational experience in facilitating these behaviors and beliefs. Overall, all students provided a perspective of care that, though reflecting similar themes, were unique and individual. Students appear intrinsically caring, though some students had difficulty expressing how caring looked in practice. This was reflective of the findings of Phillips and colleagues (2015), that students enthusiastically entered their education, but often did not have a dominant, definitive, theme regarding caring. Many students provided expected concepts related to care such as caring as a personal quality, an ability for practitioners to communicate in a caring manner, and caring as a demonstration of skill. 
Five overall themes were identified when the responses were coded and categorized including: (1) caring as it relates to time, (2) caring as a personal quality, (3) caring through demonstrating skills, (4) caring through their communication with clients, and (5) caring as a business. Concepts of: (1) caring as it relates to time, (2) caring as a personal quality, and (3) caring through their communication with clients, were consistently represented throughout.

The main concept that was not expected, but was consistently present, was the importance of time as a factor of caring. Keywords representative of temporal aspects of care were the most frequently sited words throughout the response sets. Time as a concept of caring resonated in student interviews, though all three students presented slightly different concepts of time as a carative factor (i.e., an issue of caring, an issue of professionalism, and an issue of attention). It was clear the importance of time reflected the world we live in and was related to strongly by the millennial generation. It was also reported, however, that time was important to other generations as well (e.g., a parent waiting for the doctor and patients waiting to be seen). All three interviewed students reported deficits in temporal aspects of care could be addressed through use of affective communication.

Another consistent finding of both phases one and two was how students related strongly to their negative experiences but were largely unaware of this process. When questioned, students gave similar answers about high levels of caring being an expectation rather than a benefit of good care. Bad experiences left students with lasting impressions that often led them to want to right a wrong in their own practice. This may be the reasons why each student entered their education with a unique perspective on caring. Each student's life experiences were slightly different, though at times reflecting similar concepts (i.e., issues with time), which led them to place different levels of importance on varying aspects of caring. This was similar to the results of Phillips and colleagues (2015) and Adamson and Dewar (2015), as students in those studies often had an easier time relating to what caring was not, rather than what caring was. It was further noted that the three students who were interviewed stated answering the questions based on negative experiences was not a conscious effort. The students were not readily aware they were answering based on these negative experiences until given the opportunity to reflect on their answers.

An unexpected omission in eight of the nine questionnaires was the role of culture, social, and socioeconomic factors on caring in practice. Only one student provided answers to the questionnaire that reflected the importance of cultural competence. This outcome is reflective, in some ways, of the work of Munoz (2007) that concluded most students entered professional education without culturally relevant experiences and would require these experiences to value culture in care. During the three interviews, the students often had difficulty with the concept of adjusting care based on individual life contexts. Although it is often stated that everyone should be treated equally, life contexts often directed OT treatment as the daily lives of patients impacted how therapists shaped their plan of care. Beagan (2003) indicated that medical students in her study had the same difficulty conceptualizing care in any way other than everyone 
being treated the same. These findings support the need for OT curriculum to address the issues of culture, social, and socioeconomic factors as part of a caring approach.

Finally, students all placed great importance on the role of fieldwork in developing caring behaviors. Students identified with experiencing actual patient care and had difficulty conceptualizing how these behaviors could be facilitated in the classroom. Only two students in phase one had identified something experienced within the classroom setting that affected their view of caring without being asked specifically how the classroom could change their view of caring in practice. Courses where students got to reflect on and process experiences outside of the classroom seem to have left an impression. Having the opportunity to reflect on experiences in the classroom allowed students and instructors to share differing views of how care could be applied in these situations. Students often reported value in hearing how their professors, who had years of experience, handled actual patient encounters.

For Sylvester, mentorship also played a potential role in facilitating change. Having someone with life experience help students navigate through the early stages of education and practice was valuable to him. It must be questioned if the value of mentorship is realized, however, until one engages in a successful mentoring relationship. Finally, all three interviewed students hoped their ability to be caring would not be affected by the reality of care but were aware that the stresses of "real practice" might inhibit their ability to be as caring as they foresee themselves being.

\section{Significance and Implications}

In all, this preliminary study presented a few interesting, and in some cases novel, student representations of caring in practice. Outcomes of this study also provide educators with support to enhance or develop target behaviors in students. Programs that develop curriculum based on an understanding of the presence or absence of these caring behaviors would be more likely to facilitate these behaviors during the didactic portion of training.

Providing students with opportunities to be reflective on life experiences and experiences outside of the classroom may help to facilitate these caring behaviors during in-class activities. OT programs would benefit by having students reflect on both positive and negative experiences when providing instruction. Instruction should also be inclusive of a caring perspective that is emotionally, culturally, socially, and temporally responsive. Students need to have experiences that require caring on many levels to facilitate these behaviors in later practice. Students also cited the role of coursework where open discussion allowed for processing of experiences, facilitated reflection on interactions, and allowed for feedback from instructors and classmates. This is also reflected in the students' desire to have these "real" experiences in the classroom in the form of standardized patients. Providing students with in-class simulation under the guidance of the course instructor might not only facilitate clinical reasoning and technical competence, but help to improve students' ability to handle patient interactions that require appropriate caring behaviors. 
The role of formal mentoring may also be important in developing student behaviors during the didactic portion of their education. Students would benefit from having a space where they could ask questions, make mistakes, receive constructive feedback, and hear how their experienced instructor might have handled the same situation. This would provide students with threshold experiences and provide a basis for later reflection by the student when faced with similar treatment scenarios in practice.

Lastly, students frequently indicated the importance of time as it relates to caring but often acknowledged that the reality of care might change their view of caring in the future. Educational programs would benefit from providing students realistic expectations about practice and model ways in which time could be maximized when engaging in caring patient practices. It is unclear if, when students take on the role of clinician, pragmatic issues of time will change from a carative factor to a limitation of the current health care delivery system. Students would benefit from understanding the role pragmatic reasoning plays in decision making, and ways to maximize care in a changing health care environment. Providing students with realistic views of practice requirements while still in the classroom may lead to students feeling less dissatisfied when realizing the pragmatic limitations of practice.

\section{Future Research}

The outcome of this study identified the need for future research in several areas. First, the role of time as an aspect of care should be explored further in order to identify the impact of temporal aspects of care on current practice. Further research might include identifying the importance placed by students on time in relation to caring at the start of education, and then again once the students are practicing clinicians. It would be beneficial to see if the limitations presented in actual practice leave the new therapist feeling disappointed and disillusioned or if their concept of what caring looks like in practice has shifted significantly. It would also be beneficial to understand if the educational process prepared students for this shift and decreased the role of time in their concept of caring prior to entering practice.

Second, further research needs to be conducted regarding the impact of cultural competence on caring behaviors in practice. It would be beneficial to have a greater understanding of whether students in level II fieldwork, and clinicians early in practice, can adjust care based on patient life contexts or if they continue to struggle with this dilemma. A wider study on therapist beliefs regarding treating everyone the same versus treating patients based on their cultural, social, and socioeconomic needs would be further illuminating.

Third, future research in the area of standardized patients and clinical simulation with an emphasis on developing caring behaviors in students should be explored.

Understanding how programs are successfully integrating this aspect of education into programs, and the outcomes of such programs in relation to students' caring behaviors, would provide some insight into the impact of these in-class experiences. 
Lastly, a study into how OT programs address and facilitate therapeutic use of self and caring behaviors in students would provide insight into how programs incorporate this aspect of care into the curriculum. Though there is great emphasis on developing students who are technically competent and can reason through clinical situations as a goal of the educational program, having students who are emotionally competent and able to engage in therapeutic use of self is equally important. Having a greater understanding of the impact on student behaviors and beliefs could potentially provide insight into best practices for in-class experiences regarding caring behaviors.

\section{References}

Adamson, E., \& Dewar, B. (2015). Compassionate care: Student nurses' learning through reflection and the use of story. Nurse Education Practice, 15, 155-161. https://doi.org/10.1016/i.nepr.2014.08.002

Beagan, B.L. (2003). Teaching social and cultural awareness to medical students: "It's very nice to talk about it in theory, but ultimately it makes no difference." Academic Medicine, 78(6), 605-614. https://doi.org/10.1097/00001888-200306000-00011

Care. (2014). Dictionary.com. Retrieved from http://dictionary.reference.com/browse/caring

Caring. (2014). Oxford dictionaries. Retrieved from http://www.oxforddictionaries.com/us/definition/american english/caring

Clouder, L. (2005). Caring as a 'threshold concept': Transforming students in higher education into health (care) professionals. Teaching in Higher Education, 10(4), 505-517. https://doi.org/10.1080/13562510500239141

Larin H., Benson, G., Wessel, J., Martin, L., \& Ploeg, J. (2014). Changes in emotionalsocial intelligence, caring, leadership and moral judgment during health science education programs. Journal of the Scholarship of Teaching and Learning, 14(1), 26-41. https://doi.org/10.14434/josotl.v14i1.3897

Munoz, J. P. (2007). Culturally responsive caring in occupational therapy. Occupational Therapy International, 14(4), 256-280. https://doi.org/10.1002/oti.238

Murphy, F., Jones, S., Edwards, M., James, J., \& Mayer, A. (2009). The impact of nurse education on the caring behaviors of nursing students. Nurse Education Today, 29, 254-264. https://doi.org/10.1016/i.nedt.2008.08.016

Phillips, J., Cooper, K., Rosser, E., Scammell, J., Heaslip, V., White, S., . . Harding, A. (2015). An exploration of the perceptions of caring held by students entering nursing programmes in the United Kingdom: A longitudinal qualitative study phase 1. Nurse Education in Practice, 15, 403 - 408. https://doi.org/10.1016/j.nepr.2015.05.004 